\title{
Complexities in Multiple Perspectives
}

\author{
ASHLEY STANNARD \\ London Bridge Child Care Services (Canada)
}

My story begins with an observation of a child. Watching him, I was challenged as I attempted to understand his play. $\mathrm{JH}^{\prime}$ s play and his engagement of the materials around him always occurred in silence. He did not verbally share his play with me and at times I did not understand the thoughts behind his exploration. I quickly came to wonder if I could not understand his play, how could I, as his educator, support and extend his learning?

Making my own thinking visible is where I began. I documented my observations through written notes and photographs. This process of documentation presented me with my own thinking to reflect on. At the same time, the observations I documented limited my understanding as they were shaped by my experiences and biases. Inviting my peers to collaborate and reflect on my documentation, engaging parents in discussions and considering current research about children's play, all contributed to a growing understanding of $\mathrm{JH}^{\prime}$ s play and challenged me to consider increasing possibilities. Through these multiple perspectives I learned to see things differently. I came to a greater bank of knowledge and a deeper understanding of children's play than I could have developed through my observations and reflections alone. This experience has shown me how many layers of understanding exist beyond what we observe in play. It has also shown me that applying a collaboration of theories and ideas to our daily practices helps to make these ideas visible.

As I explored each perspective, I thought I would find answers to many of my questions. Instead I discovered more ideas and possibilities. Each time I looked at JH's play in a different way, I discovered another layer of meaning. Each perspective held its own meaning and relating the different perspectives to each other created a web of ideas which I am still trying to comprehend. The reason why these observations became so 
complex was because I chose to pursue something which I did not understand, as I tried to support both JH's learning and my own.

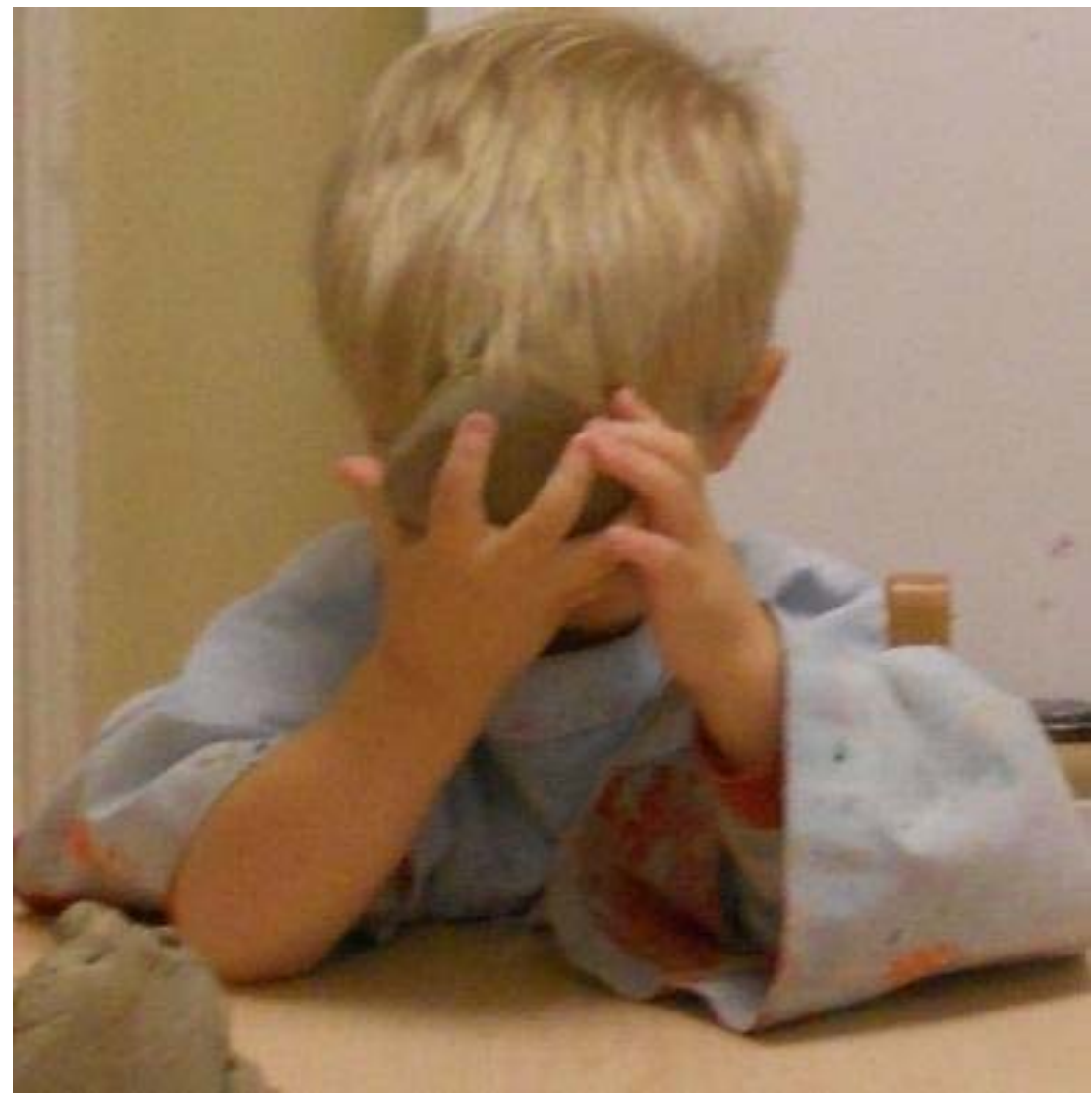

I was faced with this choice one morning as I observed JH play in silence. He explored a large piece of clay by touching it to his lips, nose, and against his ear, before placing it on his forehead (Figure 1). My mind was consumed with questions: Did the clay feel hard like a rock and yet smooth to the touch like a silky blanket? What differences has JH discovered between his sense of touch through his fingers and his forehead? Is JH exploring the idea of cold? If so, is the clay slightly cold on his finger tips and colder on his forehead? Is the cold of the clay similar to the cold of a snowflake which also touched him there? His silence consumes my thoughts and instead of words he smiles, leaving me to my own reflections.

These silent explorations, though challenging, are the most rewarding. With these questions left unanswered, the possibilities are limited only by my imagination. I knew there was more to this situation I did not understand than what I did, I continued to pursue my many questions.

Working independently as an educator, I do not always have the luxury of another perspective. It can be challenging at times to turn towards a peer for another perspective or join me in observation. When there are opportunities for collaboration, I must choose which observations I share with my peers and which ones remain for self-reflection. Observations fall through the cracks, unseen and unheard by anyone other than myself. 
It is important for me as an educator, to be dedicated to my daily practice to challenge and push myself to the next level of thinking.

Reflecting on my initial observations of JH's play, I turned to photographs in hopes of finding a photograph I did not remember taking, or even finding a glimpse of his play in a photo of another child's exploration. I felt I was missing something, only observing a fragment of his play. Photographic documentation freezes play in time so that it can be seen, reflected, and interpreted over and over again. New meaning and understanding may become evident.

Examining these photos, I saw evidence of more ideas JH may have been exploring:
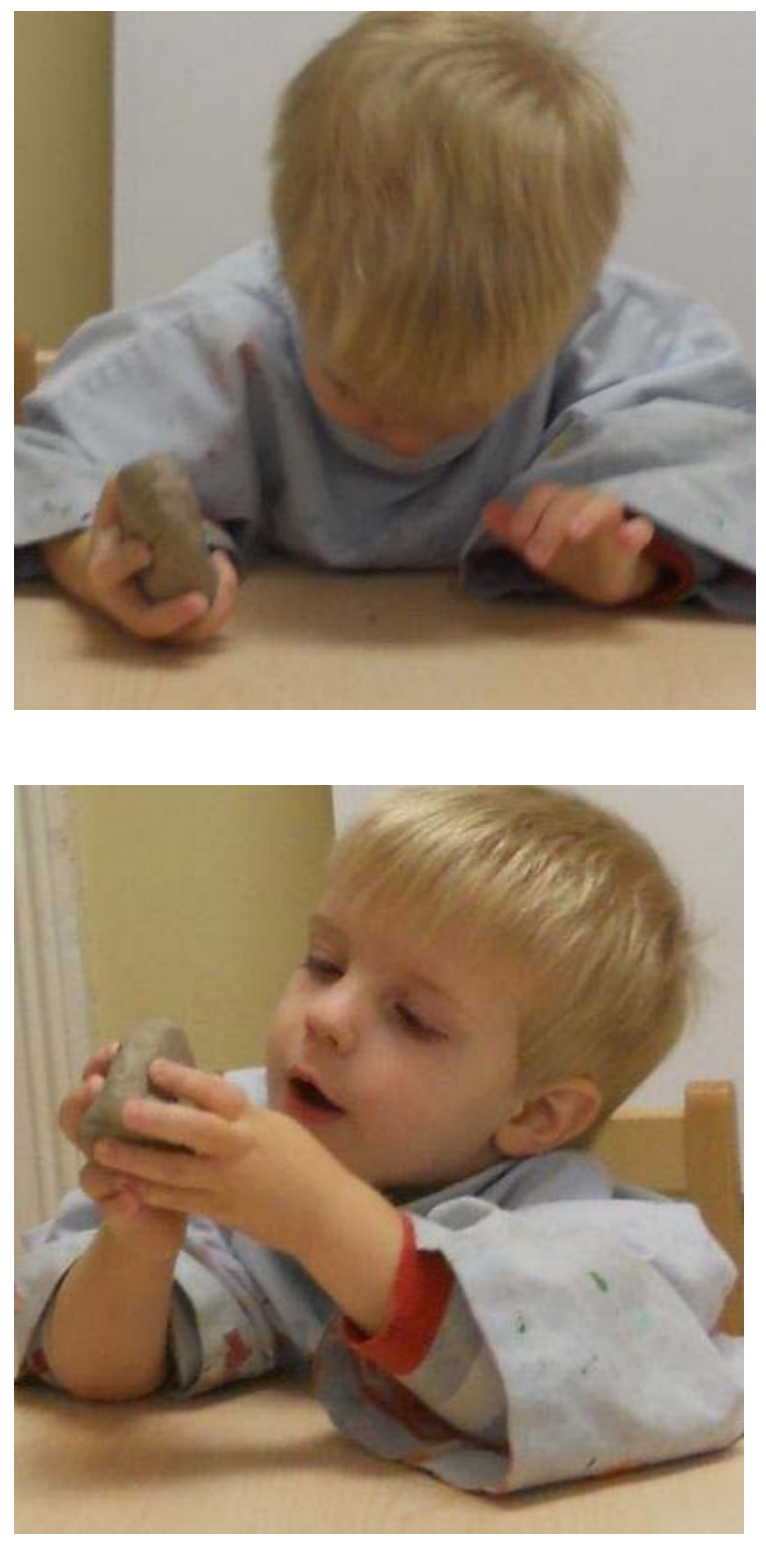

In this photo, JH is observing a tiny piece of clay on the table. I did not see him take apart, create marks, or re-structure the physical formation of the clay in any manner. How did the piece of clay get there? Was it there throughout his exploration? Did it fall from his large piece of clay? Did he scratch the piece of clay with his finger and find this tiny piece under his nail? If this was the situation, maybe he did not like the messy feel of this experience or the feeling of the clay under his nail, which prevented him from continuing to take the clay apart.

I noticed in this photo (Figure 3), how JH's facial expression has changed while he explores the clay. I can almost hear him say "oh," by looking at his expression. It feels as though something new or different has caught his attention about his clay. I am also wondering what it is that he sees. The photograph and placement of his hands on his clay prevents me from further sharing in this experience. 

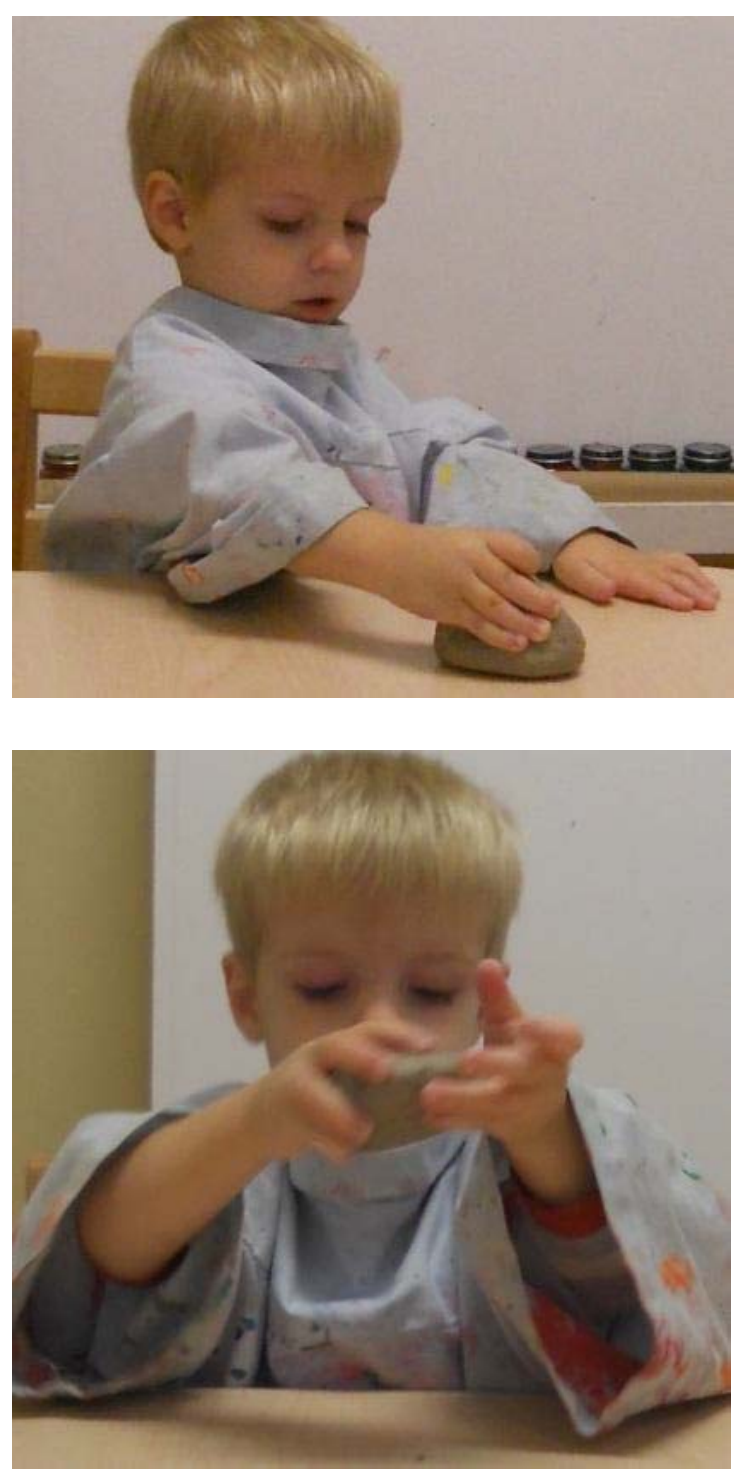

In this photo, I noticed how far away the clay is in relation to him. Yet he is still engaged with it because his hand is touching it. I am wondering if he had made a discovery that he was not sure about and therefore, pushed the clay away from him to a safer distance for exploration.

With this photo I noticed his focus is not on the piece of clay he is holding but down towards the table. I wonder if a tiny piece of clay has captured his curiosity on the table. Maybe the clay has left impressions on the table $\mathrm{JH}$ is left to explore. Is $\mathrm{JH}$ moving the clay around in the air as he explores shadows the piece of clay has left for him to engage with?

I thought having the opportunity to reflect on these photographs would provide me with greater insight into JH's thinking. Instead, I found more possibilities to consider. Was this clay experience tactile in which $\mathrm{JH}$ explored ideas such as texture and temperature as I had originally thought? Or was this tactile experience the beginning of an exploration from which more ideas such as shadow or distance arose? Reflecting on these photographs has me also considering if $\mathrm{JH}$ did break the clay apart as the tiny piece of clay has engaged my curiosity. I do not believe my initial observations were incorrect in any means. The number of ways in which JH may have engaged the clay through his senses is evident in my observations of his play and through looking back to these photos. What has changed is the possibility there is something more here to understand. Studying these photographs expanded my thinking and allowed me to see many possibilities. 
After exhausting what I understood through my own experiences, I turned to research for another perspective. An article entitled Early Brain Development Research Review and Update (Schiller, 2010) provided me with new insight into JH's thinking. By engaging clay through his sense of touch, $\mathrm{JH}$ is using this concrete material to develop higher level thinking processes such as "making distinctions, recognizing relationships, organizing systems and taking on multiple perspectives." (Schiller, 2010, p.27) These abstract thinking processes provided another focus for my own research. I used this insight to re-consider his play from the perspective of these categories.

\section{Making Distinctions}

- Does the tiny piece of clay seem similar and yet so different in comparison to the larger piece of clay?

- With the clay placed over his eyes, it would have looked different (or does it from his perception) and may have appeared darker when observed through this distance.

- With the greater amount of time to explore comes a greater amount of detail that can come from this exploration. In Fig.3, it appears as though something has caught his attention. With less time in this exploration, would $\mathrm{JH}$ have made this discovery?

- Is he aware how his body is able to manipulate and cause the change, or the transformation of the clay in order to accomplish this?

\section{Recognizing Relationships}

- Cause and effect - When JH places the clay on his forehead, does it stick? Does it transfer impressions from his skin or hair to the clay?

- As he is touching the clay, moving it back and forth in his hands, does he notice how these actions change the surface texture of the clay as he leaves impressions through fingerprints, nail marks and smudges?

\section{Organizing Systems}

- Sight

- Smell

- Temperature

- Pressure (hard and soft)

- Texture (hard, soft, bumpy, silky)

- Size/Scale

- Gravity

- Distance

- Light/Dark 


\section{Taking on Multiple Perspectives}

- Exploring the clay on different areas of his body

- Lifting up the clay to look underneath

- Turning and rotating the clay in different positions

- Holding the clay with both hands, one hand, and also on the table

- Observing the clay up close to his face and also far away on the table

At this point in my research, I was more confused and overwhelmed with the possibilities that arose from observing JH's play through a multitude of perspectives. Instead of answers, the possibilities were increasing. Feeling as though I had exhausted my resources, I returned to my initial intention of introducing clay to the children. I began exploring clay, not only as an exploration for the children but as an invitation for educators to join me in deeper reflective practice in a collaborative effort. Now it was time to turn my attention to my peers, in hopes of bringing this research into richer reflection.

My colleagues offered their experiences, providing insight into $\mathrm{JH}^{\prime} \mathrm{s}$ thinking. Studying the photographs provided these educators with small glimpses of his play and provided me with additional perspectives. Together, we were curious what other senses $\mathrm{JH}$ was exploring through the clay. He was looking at the clay from multiple perspectives and touched it in different ways with his hands, but did he also explore the clay through his sense of smell, taste, or hearing? Was JH animating the clay, pretending to drive a car or truck across the table as he pushes it away, does he also pull it back? With the possibility of light, shadow, weight and explorations of gravity, we were curious how the world of science influenced his play. Throughout this pedagogical exchange of ideas, I never let go of my initial reflections. In my mind, I still see JH holding the piece of clay to his forehead and wonder about his engagement with it. This collaboration with my colleagues provided more perspectives to consider. I sit down once again, reflecting on my own observations of JH's play, curious if ideas explored in his clay were evident outside the art studio.

While initially observing $\mathrm{JH}$, I took note of ideas he could be exploring through his play. At the time I was unable to connect these ideas to other areas of his play. But now, when I have the ability to step away, I have the opportunity to make connections I could not see before. I see a sense of order and categorization in his play as he explores in different environments and with different materials. I noticed that each time JH explored a set of materials, there was always a similar aspect about them. Whether he is exploring widgets, magnetic tiles, or animals, there is always a bigger idea he is exploring such as shape, size, or colour. The red widgets could not mix with the blue, the triangle tiles could not be built at the same time with the squares, and the bear could not play on the grass with the dinosaurs. Each material which entered his play had a relationship to the others. When offered a material which did not support his play, he would kindly accept it from me, and return it to the shelf where I had found it.

The relationship JH has created between materials and the central ideas he explores in his play, brings me back to his clay exploration. What relationship did JH create 
between the clay and other materials or experiences he had? Was this the missing piece of the puzzle which would help me to understanding what ideas he was exploring?

I sought this missing piece in the very first piece of documentation I ever wrote for $\mathrm{JH}$ over a year ago. In a piece of documentation created by each of his educators, including myself, I rediscovered his interest in preparing food in the kitchen and serving it to his peers. At the time, I was curious how this interest would develop and also how it would reflect into other areas of his play. Now through the collaboration of many perspectives, I have (re-)found these relationships. Collaboratively, we were curious if the clay felt colder when JH placed it on his forehead. This idea of temperature can be seen in other areas of JH's play. In the Dramatic Center, JH explored the idea of hot by remembering to wear oven mitts when taking food out of the oven and by blowing on each plate of food before serving it to his peers. I often found $\mathrm{JH}$ exploring the concepts of hot and cold together in the hallway. He knelt on the carpet to gain a closer look at the heat radiator, placing his hands on it to feel if they were hot or cold. The interest in the radiator was more evident on cold days as there was is a window directly above it. $\mathrm{JH}$ would explore hot and cold in contrast to each other by placing his hands on the window before placing them on the radiator. He would continue to do this many times. In collaboration with his family, I learned the ideas of hot and cold were also explored at home through spending time in the kitchen with his family and experimenting in his play kitchen as well. From his imaginative exploration of kitchen play and the authentic experiences at home, we can see how JH explores the concept of temperature through different materials and environments. Now understanding this relationship, it is a possibility $\mathrm{JH}$ was also exploring temperature when he chose to place his large piece of clay on his forehead. This time dedicated to understanding $\mathrm{JH}^{\prime}$ s play has allowed a greater insight into his thinking behind his explorations.

I understand the value in seeking multiple perspectives in my work; and through time and dedication I can see a complexity which I could not before. The choice to allow this to exist through observation was something I felt I needed to do. These observations of $\mathrm{JH}$ did not need to be complicated, but when I opened my mind to a greater amount of possibilities, these observations had more to offer than what initially anticipated. My mind was curious what this play had to offer and it was this curiosity that drove the momentum through this research.

Reflecting back to the beginning of these observations, I am not sure I can say what I was looking for and I am not sure I can tell you now. I can say I learned a lot from this experience, and from this, I have gained a different type of understanding of JH's play which I am still piecing together. I still have a lot to learn. My dedication has taught me how valuable time is. With an immeasurable amount of time, a deep and richer experience was created through a continuous amount of reflection. I discovered more knowledge and made more connections because I created the time to accomplish this. I reflected on my own observations, embraced current research practices and invited others to join me in conversation. I could not have learned more by myself than I could in a collaboration of individuals who brought their own bodies of research and knowledge. In this learning experience, there was a realization of the amount of 
knowledge I have yet to uncover. This is the complexity in understanding children's play. Dedication, time, and a collaborative amount of knowledge fueled my curiosities and unanswered questions. Greater insight was gained and an understanding which I did not have before. And at exactly this point in time, everything I thought I understood comes to a stop as I meet with another question I cannot answer. The cycle begins once again. I have grown, I have learned, and I once again do not understand what I am thinking.

\section{References}

Schiller, P. Early Brain Development Research Review and Update. Exchange, November/December, 26-30.

\section{Acknowledgments}

I would like to thank the Educators who help collaborate in this initiative and my Mentor Director for assisting in edits and for handing me this opportunity. All photographs are used with permission.

About the Author

Ashley Stannard is a Registered Early Childhood Educator. She works in partnership with preschool children through London Bridge Child Care Services.

(C) Copyright 2015. The author, ASHLEY STANNARD, assigns to the University of Alberta and other educational and non-profit institutions a non-exclusive license to use this document for personal use and in courses of instruction provided that the article is used in full and this copyright statement is reproduced. The author also grants a non-exclusive license to the University of Alberta to publish this document in full on the World Wide Web, and for the document to be published on mirrors on the World Wide Web. Any other usage is prohibited without the express permission of the authors. 